\title{
Effect of ASA dose doubling versus switching to clopidogrel on plasma inflammatory markers concentration in patients with type 2 diabetes and high platelet reactivity: The AVOCADO study
}

\author{
Marek Rosiak ${ }^{1^{*}}$, Marek Postula ${ }^{2 *}$, Agnieszka Kaplon-Cieslicka ${ }^{1}$, \\ Agnieszka Kondracka ${ }^{3}$, Ewa Trzepla ${ }^{1}$, Andrzej Czlonkowski ${ }^{2}$, \\ Piotr K. Janicki ${ }^{4}$, Krzysztof J. Filipiak ${ }^{1}$, Grzegorz Opolski ${ }^{1}$
}

${ }^{1}$ Department of Cardiology, Medical University of Warsaw, Poland

${ }^{2}$ Department of Experimental and Clinical Pharmacology, Medical University of Warsaw, Poland

${ }^{3}$ Department of Internal Medicine and Endocrinology, Medical University of Warsaw, Poland

${ }^{4}$ Department of Anesthesiology, Penn State College of Medicine, Hershey, Pennsylvania, USA

\begin{abstract}
Background: The aim of the study was to compare the effects of 2 strategies of antiplatelet treatment (i.e., $150 \mathrm{mg}$ ASA vs. $75 \mathrm{mg}$ clpoidogrel) on plasma level of inflammatory markers in type 2 diabetes mellitus (T2DM) patients with high platelet reactivity (HPR).

Methods: Study cohort consisted of 304 T2DM patients on chronic ASA therapy (75 mg per day) participating in the Aspirin Versus/Or Clopidogrel in Aspirin-resistant Diabetics inflammation Outcomes (AVOCADO) study. Patients with HPR defined as Platelet Function Analyzer (PFA)-100 collagenelepinephrine closure time $(C E P I-C T)<193 s(n=80)$ were randomized to $150 \mathrm{mg}$ of ASA or $75 \mathrm{mg}$ of clopidogrel in 2:3 ratio, respectively. Concentrations of the selected inflammatory markers, including tumor necrosis factor (TNF)- $\alpha$, interleukin (IL)-6, soluble CD40 ligand (sCD40L), and high sensitivity C-reactive protein (hsCRP), were measured and compared in both treatment groups before and after 8 weeks of treatment in both groups.
\end{abstract}

Results: Out of 234 patients included into final analysis, the total of $34.2 \%(n=80)$ patients displayed HPR, of which $14.1 \%(n=33)$ were randomized into $150 \mathrm{mg}$ of ASA group and $20.1 \%(n=47)$ into $75 \mathrm{mg}$ of clopidogrel group. Treatment with clopidogrel was a positive predictor (stepwise multiple regression analysis) of reduction of $s C D 40 L$ concentration (odds ratio [OR] 4.15; $p=0.013$ ), while treatment with $150 \mathrm{mg} A S A$ was a positive predictor of reduction of IL-6 concentration (OR 4.38; $p=0.033$ ). There was no statistically significant differences between clopidogrel and ASA $150 \mathrm{mg}$ treatment in respect to predictive value for decreased hsCRP concentrations or increased TNF- $\alpha$ concentrations.

Conclusions: Increasing the dose of ASA from $75 \mathrm{mg}$ to $150 \mathrm{mg}$ daily or switching ASA $75 \mathrm{mg}$ to clopidogrel $75 \mathrm{mg}$ daily may reduce concentrations of some inflammatory markers (in particular hsCRP, IL-6 and CD40L) in T2DM patients with HPR treated previously with $75 \mathrm{mg}$ of ASA. (Cardiol J 2013; 20, 5: 545-551)

Key words: platelets, antiplatelet, inflammation, cardiovascular

Address for correspondence: Marek Postula, MD, Department of Experimental and Clinical Pharmacology, Medical University of Warsaw, ul. Krakowskie Przedmieście 26/28, 02-097 Warszawa, Poland, tel: +48 2282621 16,

e-mail: mpostula@wum.edu.pl

*These authors contributed equally to this work.

Received: 03.01.2013 Accepted: 27.02.2013 


\section{Introduction}

Patients with type 2 diabetes (T2DM) have a 2- to 4-fold higher risk for cardiovascular (CV) disease as compared with non-diabetic individuals [1]. It is caused partly by hypercoagulable state as evidenced by high platelet reactivity (HPR) [2]. Etiology of HPR is complex, and seems to be a result of hyperglycemia, metabolic disorders, oxidative stress and inflammation [3]. In particular, T2DM patients have higher concentrations of inflammatory markers, platelet activation and coagulation markers than healthy subjects [4-6]. Moreover, higher concentrations of inflammatory markers correlate with increased CV risk [7, 8]. There have been very few studies that evaluated the anti-inflammatory effects of antiplatelet therapy in T2DM patients $[9,10]$. According to the American Diabetes Association guidelines, high-risk T2DM patients should be treated with low doses of acetylsalicylic acid (ASA) in primary or secondary prevention of myocardial infarction (MI) [11]. However, some of T2DM patients experience $\mathrm{CV}$ events despite treatment with ASA and that might be, at least in part, related to HPR, despite treatment with low-doses of ASA [12, 13].

In spite of recent advances in antiplatelet therapy the optimal treatment strategy is yet to be established in patients with HPR despite treatment with low dose of ASA (i.e. $75 \mathrm{mg}$ per day). Previous studies demonstrated that T2DM patients treated with $162 \mathrm{mg}$ ASA had lower incidence of HPR than those receiving $81 \mathrm{mg}$, however increasing the dose to $325 \mathrm{mg}$ had not resulted in further improvement in terms of platelet reactivity [14, 15]. Also in the AVOCADO study switching to higher dose of ASA reduced platelet reactivity in T2DM patients with HPR initially treated with $75 \mathrm{mg}$ of ASA per day [16].

It was hypothesized that dose-related inhibition of platelet aggregation may be due to effects of ASA beyond inhibition of its primary target cyclooxygenase (COX-1) by acetylation and was termed a non-COX-1 effect [15]. Thus, in our study shear dependent platelet functions were measured with less COX-1 inhibition dependent device Platelet Function Analyzer (PFA)-100.

The aim of our prospective and randomized study was to compare the effects of 2 strategies of antiplatelet treatment (150 mg ASA vs. $75 \mathrm{mg}$ clopidogrel) on the plasma level of selected inflammatory mediators (hsCRP, IL-6, TNF- $\alpha$, sCD40L) in T2DM patients with established HPR, (diagnosed with PFA-100 collagen/epinephrine closure time (CEPI-CT) assay during previous treatment with $75 \mathrm{mg}$ of ASA).

\section{Methods}

The study subjects were recruited consecutively from patients with T2DM (participating in a multi-center, prospective, randomized, and open-label Aspirin Versus/Or Clopidogrel in Aspirin-resistant Diabetics inflammation Outcomes (AVOCADO) study presenting to the outpatient clinic of the Central Teaching Hospital of the Medical University of Warsaw. The full characterization of the study population, including the inclusion and exclusion criteria were published previously [17]. Briefly, the Caucasian subjects with T2DM were recruited who, at the time of enrollment, had been taking ASA tablets at the dose of $75 \mathrm{mg}$ per day for at least 3 months for primary or secondary prevention of myocardial infarction (MI). No clopidogrel or antiplatelet drugs other than ASA were used in any of the investigated patients. All patients had been taking oral antidiabetic agents and/or insulin for at least 6 months; diet-controlled diabetic patients were not included. Compliance to ASA therapy at the study entry was determined based upon the patient's own statement and serum thromboxane $\mathrm{B}_{2}\left(\mathrm{sTXB}_{2}\right)$ level measurement.

\section{Blood sample and assay procedures}

Blood samples were taken in the morning 2-3 h after the last ASA dose. Regular laboratory testing was performed using standard laboratory techniques. The concentration of functional epitope of the von Willebrand factor (vWF) molecule (vWF:Ag) was measured in citrate plasma samples using an enzyme immunoassay kit according to the manufacturer's instructions (vWF Activity Kit, American Diagnostica Inc., USA). Serum $\mathrm{TXB}_{2}$ concentrations were measured also with an enzyme immunoassay (EIA) kit according to the manufacturer's instructions (EIA kits, Cayman Chemicals, Ann Arbor, MI, USA). Each lot of $\mathrm{TXB}_{2}$ EIA kit was tested for the impact of interferences. The correlation of results in three dilutions of 5 random samples was assessed, as was proposed in kit protocol. The decision to use the assay without purification was taken after analysis of results, as differences of results did not exceed $20 \%$. Samples with results outside the standard curve were re-assayed with appropriate dilutions. The compliance with ASA treatment was defined by the $\mathrm{sTXB}_{2}$ levels below $7.2 \mathrm{ng} / \mathrm{mL}$ [13].

ELISAs were used to determine concentrations of tumor necrosis factor (TNF)- $\alpha$ (Quanti- 
kine ${ }^{\circledR}$ HS ELISA Human TNF- $\alpha$ Immunoassay), interleukin (IL)-6 (Quantikine ${ }^{\circledR}$ HS ELISA Human IL-6 Immunoassay; both R\&D Systems, Inc., Minneapolis, USA) and soluble CD40 ligand (sCD40L; Human soluble CD40 Ligand Immunoassay, R\&D Systems, Inc., NE, USA), and high sensitivity C-reactive protein (hsCRP) concentrations were assessed using Cobas Integra 800 (Roche, Basel, Switzerland).

\section{Analysis of platelet functions}

Platelet reactivity was measured with PFA-100 assay (Dade-Behring International, Inc., Newark, DE, USA). These assays were performed as described in detail previously [13]. In current study, normal platelet reactivity on ASA therapy with a PFA-100 was defined as CEPI-CT $\geq 193 \mathrm{~s}$ (the manufacturer's lower limit of the normal range for aspirin-free healthy controls). Patients with HPR defined as CEPI-CT < $193 \mathrm{~s}$ were randomized to double dose (150 mg) of ASA or $75 \mathrm{mg}$ of clopidogrel in 2:3 ratio, respectively. After 8 weeks of follow-up period inflammatory markers concentrations were re-assayed.

\section{Statistical analysis}

Normally distributed continuous variables were presented as means $\pm \mathrm{SD}$, whereas variables with a highly skewed distribution were presented as medians (interquartile ranges). Categorical variables were presented as frequencies (percentages). Normality of distribution was assessed using graphical methods. Differences between groups were analyzed using Student's $t$-test, the Mann-Whitney U-test, the $\chi^{2}$ or Cochran-Mantel-Haenszel test, as appropriate. Selected variables were checked for associations with changes in inflammatory markers concentrations using a univariate and multivariate stepwise logistic regression models. The results were presented as odds ratios (OR) with their $95 \%$ confidence intervals (CI). A 2 -sided p-value of $<0.05$ was considered significant.

\section{Power analysis}

We were planning a prospective study of 2 independent experimental groups (clopidogrel $75 \mathrm{mg}$ vs. ASA $150 \mathrm{mg}$ ), with 3 patients treated with clopidogrel $75 \mathrm{mg}$ treated patients per 2 patients treated with ASA $150 \mathrm{mg}$ (ratio 3:2). Prior data indicate that the response rate (defined as percentage of patients in the groups with decreased or increased of any measured inflammatory marker) among clopidogrel treated patients was 0.5 . If the true response rate for ASA-treated subjects differs by 0.35 , we will need to study at least 28 ASA $150 \mathrm{mg}$ treated patients and at least 39 clopidogrel $75 \mathrm{mg}$ treated subjects (total number of subjects at least 77) to be able to reject the null hypothesis that the response rates for subjects in both treated group are equal with probability (power) 0.8 . The Type I error probability associated with this test of this null hypothesis is 0.05 . We used an Fisher's exact test to evaluate this null hypothesis.

\section{Results}

From the initially enrolled 304 patients, complete clinical data and blood samples finally became available for 260 patients. Subsequently, 8 patients were eliminated from the analysis based on suspected ASA non-compliance ( $\mathrm{sTXB}_{2}$ concentrations $>7.2 \mathrm{ng} / \mathrm{mL}$ ). Baseline characteristics are presented in Table 1 . Twenty patients were excluded from the analysis due to elevated concentrations of hsCRP (> $10 \mathrm{mg} / \mathrm{L})$ indicating potential subclinical infection. Out of 234 patients included into final analysis $34.2 \%(\mathrm{n}=80)$ patients had HPR of which $14.1 \%(\mathrm{n}=33$ ) were randomized to $150 \mathrm{mg}$ of ASA group and 20.1\% ( $\mathrm{n}=47)$ to $75 \mathrm{mg}$ of clopidogrel group.

After 8 weeks of treatment with either medication we observed a significant reduction of hsCRP: $\Delta$ (change in concentrations of marker after 8 weeks of follow-up) $=-0.4(-1.3-0.2) ; \mathrm{p}=0.006$ and IL-6: $\Delta=-0.714(-1.435-0.150) ; \mathrm{p}<0.001$, as well an increase of TNF- $\alpha: \Delta=0.552(0.064$ $-0.931) ; p<0.001$ in group receiving $150 \mathrm{mg}$ of ASA. We also observed a significant reduction of hsCRP: $\Delta=-0.3(-1.0-0.1) ; \mathrm{p}=0.008$, no change for Il-6: $\Delta=0.045(-1.247-0.779) ; \mathrm{p}=0,587$ and an increase of TNF- $\alpha$ : $\Delta=0.778(0.129-1.670)$; $\mathrm{p}<0.001$ in group receiving clopidogrel. The calculated response rate for hsCRP and TNF- $\alpha$ in both experimental groups was similar and did not differ significantly ( $p>0.05$ ) between $150 \mathrm{mg}$ ASA and 75 mg clopidogrel group by the Fisher's exact test analysis. In a Mann-Whitney test analysis we found a significant difference in the magnitude of change for IL- 6 concentrations between groups $(-0.714$ in $150 \mathrm{mg}$ of ASA group vs. 0.024 in clopidogrel group; $\mathrm{p}=0.034)$. There was also significantly higher percentage of patients with IL-6 reduction in group receiving $150 \mathrm{mg}$ of ASA than in group receiving clopidogrel (72.7\% vs. $48.9 \%$, respectively; $\mathrm{p}=0.033$ by Fisher's exact test).

There was no difference in the change of concentrations of sCD40L between studied groups, but there was a significantly higher percentage 
Table 1. Demographic and clinical characteristics of the study patients $(n=254)$.

\begin{tabular}{|c|c|}
\hline \multicolumn{2}{|l|}{ Demographics } \\
\hline Male & $136(53.5 \%)$ \\
\hline Age [years] & $67.1 \pm 8.5$ \\
\hline $\mathrm{SBP}[\mathrm{mm} \mathrm{Hg}]$ & $141.3 \pm 19.3$ \\
\hline $\mathrm{DBP}[\mathrm{mm} \mathrm{Hg}]$ & $79.8 \pm 11.6$ \\
\hline $\mathrm{BMI}\left[\mathrm{kg} / \mathrm{m}^{2}\right]$ & $30.7 \pm 4.9$ \\
\hline WHR & $0.96 \pm 0.08$ \\
\hline \multicolumn{2}{|l|}{ Comorbidities } \\
\hline Hypertension & $235(92.5 \%)$ \\
\hline Coronary artery disease & $137(53.9 \%)$ \\
\hline Prior MI & $77(30.3 \%)$ \\
\hline Dyslipidemia & $214(84.3 \%)$ \\
\hline Chronic heart failure & $94(37.2 \%)$ \\
\hline Prior stroke and/or TIA & $28(11.0 \%)$ \\
\hline History of smoking & $149(58.7 \%)$ \\
\hline Current smoking & $26(10.2 \%)$ \\
\hline \multicolumn{2}{|l|}{ Concurrent medications } \\
\hline Metformin & $162(63.8 \%)$ \\
\hline Insulin & $83(32.7 \%)$ \\
\hline Beta-blockers & $183(72.0 \%)$ \\
\hline ACE inhibitors & $168(66.1 \%)$ \\
\hline Statins & $184(72.4 \%)$ \\
\hline Proton pump inhibitors & $31(12.2 \%)$ \\
\hline \multicolumn{2}{|l|}{ Biochemical parameters } \\
\hline WBC $\left[10^{3} / \mu \mathrm{L}\right]$ & $7.1 \pm 2.0$ \\
\hline $\mathrm{HGB}[\mathrm{g} / \mathrm{dL}]$ & $13.9 \pm 1.3$ \\
\hline HTC [\%] & $41.6 \pm 3.7$ \\
\hline PLT $\left[10^{3} / \mu \mathrm{L}\right]$ & $228.8 \pm 61.3$ \\
\hline MPV $[\mathrm{fl}]$ & $9.9 \pm 1.2$ \\
\hline $\begin{array}{l}\text { eGFR (MDRD) [mLmin/ } \\
\left./ 1.73 \mathrm{~m}^{2}\right]\end{array}$ & $70.9 \pm 20.4$ \\
\hline $\mathrm{HbA} 1 \mathrm{c}[\%]$ & $7.0 \pm 1.3$ \\
\hline Total cholesterol [mg/dL] & $164.9 \pm 40.0$ \\
\hline $\mathrm{HDL}[\mathrm{mg} / \mathrm{dL}]$ & $48.7 \pm 13.9$ \\
\hline $\mathrm{LDL}[\mathrm{mg} / \mathrm{dL}]$ & $88.9 \pm 33.5$ \\
\hline Triglycerides [mg/dL] & $136.7 \pm 68.3$ \\
\hline VWF [\%] & $144.7 \pm 57.4$ \\
\hline CEPI-CT [s] & $257(172-300)$ \\
\hline $\mathrm{sTXB} \mathrm{B}_{2}[\mathrm{pg} / \mathrm{mL}]$ & $153.2(45.7-546.3)$ \\
\hline \multicolumn{2}{|c|}{ Inflammatory markers $(n=234)^{*}$} \\
\hline hsCRP [mg/L] & $2.3(1.4-4.0)$ \\
\hline $\mathrm{sCD} 40 \mathrm{~L}[\mathrm{ng} / \mathrm{mL}]$ & $0.582(0.349-0.909)$ \\
\hline TNF- $\alpha[\mathrm{pg} / \mathrm{mL}]$ & $1.753(1.244-2.292)$ \\
\hline IL-6 [pg/mL] & $2.193(1.504-3.672)$ \\
\hline \multicolumn{2}{|c|}{$\begin{array}{l}\text { *Inflammatory markers concentrations after excluding patients } \\
\text { with hsCRP > } 10 \mathrm{mg} / \mathrm{L} \text {; SBP - systolic blood pressure; } \\
\text { DBP - diastolic blood pressure; BMI - body mass index; } \\
\text { WHR - waist-to-hip ratio; MI - myocardial infarction; } \\
\text { TIA - transient ischemic attack; ACE - angiotensin converting } \\
\text { enzyme; WBC - white blood cells count; HGB - hemoglobin; } \\
\text { HTC - hematocrit; PLT - platelet count; MPV - mean platelet } \\
\text { volume; eGFR - estimated glomerular filtration rate; } \\
\text { HbA1c - glycosylated hemoglobin; HDL - high density lipo- } \\
\text { proteins; LDL - low density lipoproteins; vWF - von Wille- } \\
\text { brand factor; CEPI-CT - collagen/epinephrine closure time; } \\
\text { sTXB } \text { s }_{2} \text { - serum thromboxane } \mathrm{B}_{2} \text { concentration; hsCRP - high- } \\
\text {-sensitivity C-reactive protein; sCD } 40 \mathrm{~L} \text { - soluble CD40 ligand; } \\
\text { TNF- } \alpha \text { - tumor necrosis factor-alpha; IL-6 - interleukin-6 }\end{array}$} \\
\hline
\end{tabular}

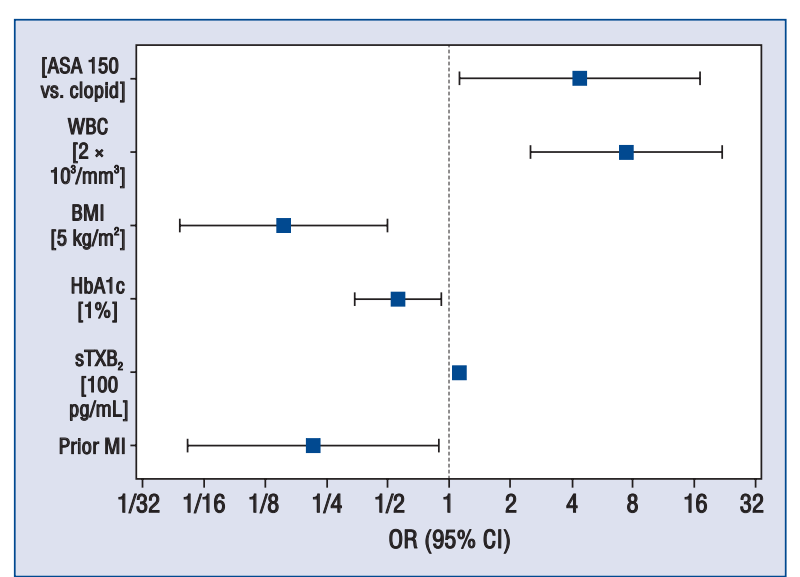

Figure 1. Factors influencing reduction of interleukin-6 (IL-6) concentrations in multivariate analysis; ASA 150 - patients randomized to receiving $150 \mathrm{mg}$ of acetylsalicylic acid; clopid - patients randomized to receiving $75 \mathrm{mg}$ of clopidogrel; WBC - white blood cells count; $\mathrm{BMI}$ - body mass index; HbA1c - glycosylated hemoglobin; $\mathrm{TTX}_{2}$ - serum thromboxane- $\mathrm{B}_{2} ; \mathrm{Ml}$ - myocardial infarction; $\mathrm{OR}$ - odds ratio; $\mathrm{Cl}$ - confidence interval.

of patients in clopidogrel group with sCD40L reduction than in group taking $150 \mathrm{mg}$ of ASA $(61.7 \%$ vs. $33.3 \%$, respectively; $\mathrm{p}=0.012$, by Fisher's exact test).

In stepwise multiple logistic regression analysis adjusted to age and gender, treatment with $150 \mathrm{mg}$ ASA (OR 4.38; 95\% CI $1.13-17.02 ; \mathrm{p}=0.033$ ) and higher white blood count (WBC) (for each $2 \times$ $\times 10^{3} / \mathrm{mm}^{3}$ : OR 7.43; 95\% CI 2.51-21.97; $\left.<0.001\right)$ were positive predictors of reduction of IL- 6 concentration, while higher glycosylated hemoglobin (HbA1c) (for each 1\%: OR 0.56; 95\% CI $0.34-0.91$; $\mathrm{p}=0.02$ ) and body mass index (BMI) (for each $5 \mathrm{~kg} / \mathrm{m}^{2}$ : OR 0.15; 95\% CI $\left.0.05-0.50 ; \mathrm{p}=0.002\right)$ and history of MI (OR 0.21; 95\% CI $0.05-0.88$; $\mathrm{p}=0.033$ ) were negative predictors of reduction of IL-6 concentration (Fig. 1). Patients treated with statins had higher chance of reduction of hsCRP concentration (OR 3.72; 95\% CI 1.05-13.2; $\mathrm{p}=0.042$ ), while patients with history of MI had lower chance of reduction of this parameter (OR $0.25 ; 95 \%$ CI $0.08-0.81 ; p=0.021)$. Only higher $\mathrm{HbA} 1 \mathrm{c}$ was a negative predictor of reduction of TNF- $\alpha$ concentration (OR for reduction of TNF- $\alpha$ : $0.287 ; 95 \%$ CI $0.09-0.87 ; p=0.027)$. There was no difference in change of hsCRP and TNF- $\alpha$ concentrations between studied groups.

Treatment with clopidogrel was a positive predictor of reduction of $\mathrm{sCD} 40 \mathrm{~L}$ concentration 


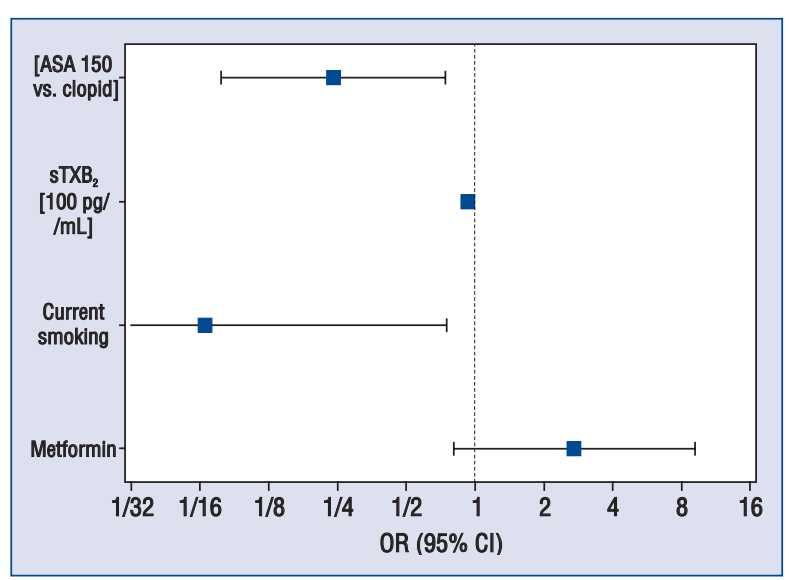

Figure 2. Factors influencing reduction of soluble CD40 ligand (sCD40L) concentrations in multivariate analysis; ASA 150 - patients randomized to receiving $150 \mathrm{mg}$ of acetylsalicylic acid; clopid - patients randomized to receiving $75 \mathrm{mg}$ of clopidogrel; $\mathrm{sTXB}_{2}$ - serum thromboxane- $\mathrm{B}_{2}$; OR - odds ratio; $\mathrm{Cl}$ - confidence interval.

(OR 4.15; 95\% CI $1.34-12.82 ; \mathrm{p}=0.013$ ) while current smoking (OR 0.93; 95\% CI 0.87 - 0.99; $\mathrm{p}=0.028)$ and higher $\mathrm{sTXB}_{2}$ concentrations (OR 0.93; $0.87-0.99 ; \mathrm{p}=0.024$ ) were negative predictors of reduction of this parameter (Fig. 2).

\section{Discussion}

The present study demonstrate that treatment with either $150 \mathrm{mg}$ of ASA or $75 \mathrm{mg}$ of clopidogrel result in significant reduction of hsCRP, sCD40L, IL-6 (only in and ASA treated patients) and in increase of TNF- $\alpha$ inflammatory markers concentration in T2DM patients with stable coronary artery disease (CAD) or multiple risk factors for CAD. No statistically significant differences were observed between the treatment groups in respect to the magnitude of changes (defined as the fraction of patients treated with ASA or clopidogrel with decreased concentrations of hsCRP or increased concentration of TNF- $\alpha$ ). Treatment with ASA vs. clopidogrel caused however different effect on response rate related to $\mathrm{Il}-6$ and $\mathrm{sCD} 40 \mathrm{~L}$ inflammatory markers (i.e., significant increase in the response rate for decreased IL-6 in only ASA $150 \mathrm{mg}$ group, and significant increase in the response for decreased sCD40L only in clopdogrel group). Moreover, the results of this study show that both antiplatelet therapies were less effective in terms of their anti-inflammatory activity in patients with higher BMI, currently smoking and with a history of MI.
Several previous studies demonstrated anti-inflammatory effect of low doses of ASA and clopidogrel, mainly in patients with CAD [18-25]. The results of subanalysis of Physician's Health Study suggested that cardioprotective effect of ASA correlated with its anti-inflammatory effect [26]. There are very few studies assessing the effect of different doses of ASA on inflammatory state in patients with T2DM. Hovens et al. [9] demonstrated that there was no difference in hsCRP and IL-6 concentrations in patients with T2DM treated with either $100 \mathrm{mg}$ or $300 \mathrm{mg}$ of ASA, or placebo.

In our study doubling the dose of ASA in patients with HPR resulted in a significant reduction of hsCRP and IL- 6 concentrations with more than 4 -fold higher chance of IL-6 reduction than in a group treated with clopidogrel. Herder et al. [27] observed that high IL-6 levels in patients with diabetes were associated with increased risk for primary CV events (MI, stroke and CV death). Thus, doubling the dose of ASA by reducing IL- 6 and hsCRP concentrations could be more effective in reducing the $\mathrm{CV}$ risk of patients with diabetes and HPR during treatment with $75 \mathrm{mg}$ of ASA, but this hypothesis should be confirmed in further larger studies with well defined clinical end-points.

In the Diabetes Heart Study higher hsCRP concentration was a predictor of mortality in patients with T2DM [28]. In our study both antiplatelet treatment strategies resulted in significant reduction in hsCRP concentrations. In multivariate analysis the history of MI was a negative predictor of reduction of hsCRP concentrations (OR 0.25; $95 \%$ CI $0.08-0.80 ; \mathrm{p}=0.021)$. According to the results of recent meta-analysis, treatment with ASA in primary prevention of CV diseases remains of uncertain value in diabetic population [29]. Patients with a history of MI tend to have higher concentrations of hsCRP and treatment with ASA results in more reduction of MI risk in patients with higher levels of hsCRP than in patients with lower concentrations of hsCPR [26, 30, 31]. However, in our study patients with T2DM and with a history of MI which were chronically treated with $75 \mathrm{mg}$ of ASA had lower baseline hsCRP concentrations than patients treated with ASA in primary prevention of MI, although due to small number of subjects the difference was not statistically significant. Moreover, treatment with higher dose of ASA or switching from ASA to clopidogrel resulted in additional reduction of hsCRP concentrations especially in patients without history of MI. This may indicate that patients treated with $75 \mathrm{mg}$ of ASA in primary prevention of MI might require 
modification of antiplatelet therapy, higher doses of ASA or switching to clopidogrel, which may cause additional benefit in terms of reducing hsCRP levels in this subgroup of patients.

In our study the median of SCD40L concentrations after 8 weeks of treatment with clopidogrel increased, but we observed a decrease in $\mathrm{SCD} 40 \mathrm{~L}$ concentrations in almost twice as many patients in this group as in group treated with $150 \mathrm{mg}$ of ASA. There was also more than 4-fold higher chance of reduction in $\mathrm{SCD} 40 \mathrm{~L}$ concentration in patients treated with clopidogrel than in patients treated with $150 \mathrm{mg}$ of ASA. Several studies have indicated that levels of circulating sCD40L are significantly higher in patients with acute MI or unstable angina and that $\mathrm{sCD} 40 \mathrm{~L}$ may be the marker of high risk population among patients with acute coronary syndrome [32, 33]. Therefore, it was suggested that $\mathrm{sCD} 40 \mathrm{~L}$ may be a therapeutic target and the reduction of its concentrations may lead to improved clinical outcome [34]. Our study is the first showing that clopidogrel is much more effective than ASA in reducing $\mathrm{SCD} 40 \mathrm{~L}$ concentrations in diabetic population, but it seems to be less effective in smokers than in non-smoking population. These results may indicate, that switching to clopidogrel, along with smoking cessation, could be an optimal therapy in patients with T2DM and HPR during treatment with $75 \mathrm{mg}$ of ASA in terms of reduction of inflammatory markers concentrations.

\section{Limitations of the study}

The inherent limitations of open-label design apply to this study. Another limitation is related to the choice of the test for measurement of platelet reactivity for diagnosis of HPR. Light transmission aggregometry (LTA) is considered to be the gold standard platelet function test but is poorly standardized, requires a specialist laboratory and is unlikely to be used widely in routine clinical practice [35]. Moreover LTA measures more specifically effects of COX-1 dependent pathway of platelet activation, while PFA- 100 by using different platelet agonists, measures more global platelet reactivity [36].

\section{Conclusions}

Increasing the dose of ASA from $75 \mathrm{mg}$ to $150 \mathrm{mg}$ daily or switching ASA $75 \mathrm{mg}$ to clopidogrel $75 \mathrm{mg}$ daily reduce concentrations of hsCRP, IL- 6 and sCD40L inflammatory markers in T2DM patients with HPR and treated previously with $75 \mathrm{mg}$ of ASA. Doubling the dose of ASA was more successful in reducing IL-6, while clopidogrel was better in reducing sCD40L. Anti-inflammatory effects of these 2 strategies were smaller in currently smoking patients with a history of MI, poorer long-term glycemic control and higher BMI.

\section{Acknowledgements}

The AVOCADO study was supported financially as part of the research grant from the Polish Pharmaceutical Company ADAMED [grant number: 1WR DAR1/2007]. The authors would like to thank dr Agnieszka Serafin for helping in preparing the database.

\section{Conflict of interest: none declared}

\section{References}

1. Beckman JA, Creager MA, Libby P. Diabetes and atherosclerosis: epidemiology, pathophysiology, and management. JAMA, 2002; 287: 2570-2581.

2. Yazbek N, Bapat A, Kleiman N. Platelet abnormalities in diabetes mellitus. Coron Artery Dis, 2003; 14: 365-371.

3. Ferreiro JL, Gomez-Hospital JA, Angiolillo DJ. Platelet abnormalities in diabetes mellitus. Diab Vasc Dis Res, 2010; 7: 251-259.

4. Nomura S, Shouzu A, Omoto S, Nishikawa M, Fukuhara S. Significance of chemokines and activated platelets in patients with diabetes. Clin Exp Immunol, 2000; 121: 437-443.

5. Marx N, Imhof A, Froehlich J, et al. Effect of rosiglitazone treatment on soluble CD40L in patients with type 2 diabetes and coronary artery disease. Circulation, 2003; 107: 1954-1957.

6. Gokulakrishnan K, Deepa R, Mohan V, Gross MD. Soluble $\mathrm{P}$-selectin and CD40L levels in subjects with prediabetes, diabetes mellitus, and metabolic syndrome: The Chennai Urban Rural Epidemiology Study. Metabolism, 2006; 55: 237-242.

7. Schonbeck U, Varo N, Libby P, Buring J, Ridker PM. Soluble CD40L and cardiovascular risk in women. Circulation, 2001; 104: 2266-2268.

8. Ridker PM, Buring JE, Rifai N. Soluble P-selectin and the risk of future cardiovascular events. Circulation, 2001; 103: 491-495.

9. Hovens MM, Snoep JD, Groeneveld Y, Frolich M, Tamsma JT, Huisman MV. Effects of aspirin on serum C-reactive protein and interleukin-6 levels in patients with type 2 diabetes without cardiovascular disease: A randomized placebo-controlled crossover trial. Diabetes Obes Metab, 2008; 10: 668-674.

10. Angiolillo DJ, Fernandez-Ortiz A, Bernardo E et al. Clopidogrel withdrawal is associated with proinflammatory and prothrombotic effects in patients with diabetes and coronary artery disease. Diabetes, 2006; 55: 780-784.

11. Standards of medical care in diabetes: 2012. Diabetes Care, 2012; 35 (suppl. 1): S11-S63

12. Evangelista V, de Berardis G, Totani L et al. Persistent platelet activation in patients with type 2 diabetes treated with low doses of aspirin. J Thromb Haemost, 2007; 5: 2197-2203

13. Mortensen SB, Larsen SB, Grove EL, Kristensen SD, Hvas AM. Reduced platelet response to aspirin in patients with coronary artery disease and type 2 diabetes mellitus. Thromb Res, 2010; 126: e318-e322. 
14. Capodanno D, Patel A, Dharmashankar K et al. Pharmacodynamic effects of different aspirin dosing regimens in type 2 diabetes mellitus patients with coronary artery disease. Circ Cardiovasc Interv, 2011; 4: 180-187.

15. Gurbel PA, Bliden KP, DiChiara J et al. Evaluation of dose-related effects of aspirin on platelet function: Results from the Aspirin-Induced Platelet Effect (ASPECT) study. Circulation, 2007; 115: 3156-3164.

16. Rosiak M, Postuła M, Kapłon-Cieślicka A et al. The effect of doubling the dose of acetylsalicylic acid (ASA) on platelet function parameters in patients with type 2 diabetes and platelet hyperreactivity during treatment with $75 \mathrm{mg}$ of ASA: a subanalysis of the AVOCADO study. Kardiol Pol, 2013; DOI: 10.5603/KP.2013.0056.

17. Postula M, Kaplon-Cieslicka A, Rosiak M et al. Genetic determinants of platelet reactivity during acetylsalicylic acid therapy in diabetic patients: Evaluation of 27 polymorphisms within candidate genes. J Thromb Haemost, 2011; 9: 2291-2301.

18. Ikonomidis I, Andreotti F, Economou E, Stefanadis C, Toutouzas P, Nihoyannopoulos P. Increased proinflammatory cytokines in patients with chronic stable angina and their reduction by aspirin. Circulation, 1999; 100: 793-798.

19. Solheim S, Arnesen H, Eikvar L, Hurlen M, Seljeflot I. Influence of aspirin on inflammatory markers in patients after acute myocardial infarction. Am J Cardiol, 2003; 92: 843-845.

20. Jennings LK. Mechanisms of platelet activation: Need for new strategies to protect against platelet-mediated atherothrombosis. Thromb Haemost, 2009; 102: 248-257.

21. Yeh ET, Khan BV. The potential role of antiplatelet agents in modulating inflammatory markers in atherothrombosis. J Thromb Haemost, 2006; 4: 2308-2316.

22. Muhlestein JB. Effect of antiplatelet therapy on inflammatory markers in atherothrombotic patients. Thromb Haemost, 2010; 103: 71-82.

23. Azar RR, Kassab R, Zoghbi A et al. Effects of clopidogrel on soluble CD40 ligand and on high-sensitivity $\mathrm{C}$-reactive protein in patients with stable coronary artery disease. Am Heart J, 2006; 151: 521 e1-e4.

24. Saw J, Madsen EH, Chan S, Maurer-Spurej E. The ELAPSE (Evaluation of Long-Term Clopidogrel Antiplatelet and Systemic
Anti-Inflammatory Effects) study. J Am Coll Cardiol, 2008; 52: 1826-1833

25. Oqueli E, Hiscock M, Dick R. Clopidogrel resistance. Heart Lung Circ, 2007; 16 (suppl. 3): S17-S28.

26. Ridker PM, Cushman M, Stampfer MJ, Tracy RP, Hennekens CH. Inflammation, aspirin, and the risk of cardiovascular disease in apparently healthy men. N Engl J Med, 1997; 336: 973-979.

27. Herder C, Schottker B, Rothenbacher D et al. Interleukin- 6 in the prediction of primary cardiovascular events in diabetes patients: Results from the ESTHER study. Atherosclerosis, 2011; 216: 244-247.

28. Cox AJ, Agarwal S, Herrington DM, Carr JJ, Freedman BI, Bowden DW. C-reactive protein concentration predicts mortality in type 2 diabetes: The Diabetes Heart Study. Diabet Med, 2011:

29. Baigent C, Blackwell L, Collins R et al. Aspirin in the primary and secondary prevention of vascular disease: Collaborative meta-analysis of individual participant data from randomised trials. Lancet, 2009; 373: 1849-1860.

30. Yip HK, Hang CL, Fang CY et al. Level of high-sensitivity C-reactive protein is predictive of 30-day outcomes in patients with acute myocardial infarction undergoing primary coronary intervention. Chest, 2005; 127: 803-808.

31. Shi JZ, Wang LY, Zhu Y et al. OX40 ligand levels and high-sensitivity C-reactive protein levels in blood from local coronary plaque and the femoral artery in patients with acute coronary syndrome or stable angina. J Int Med Res, 2011; 39: 1275-1283.

32. Hejase de Trad C. Soluble CD40L versus myocyte enhancer factor: Predicting a prominent marker for cardiovascular disease. Conf Proc IEEE Eng Med Biol Soc, 2006; 1: 1698-1701.

33. Yan J, Wu Z, Huang Z, Li L, Zhong R, Kong X. Clinical implications of increased expression of $\mathrm{CD} 40 \mathrm{~L}$ in patients with acute coronary syndromes. Chin Med J, 2002; 115: 491-493.

34. Tousoulis D, Androulakis E, Papageorgiou N et al. From atherosclerosis to acute coronary syndromes: The role of soluble CD40 ligand. Trends Cardiovasc Med, 2010; 20: 153-164.

35. Michelson AD. Methods for the measurement of platelet function. Am J Cardiol, 2009; 103: 20A-26A.

36. Harrison P, Frelinger AL, $3^{\text {rd }}$, Furman MI, Michelson AD. Measuring antiplatelet drug effects in the laboratory. Thromb Res, 2007; 120: 323-336. 